Research Paper

\title{
Difference of genomic copy numbers alterations between hairy cell leukemia-variant and classical hairy cell leukemia: a pilot retrospective study in Chinese
}

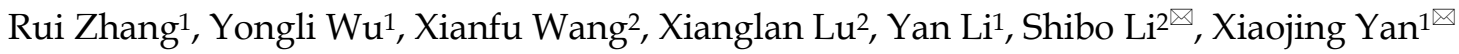 \\ 1. Department of Hematology, The First Affiliated Hospital of China Medical University, Shenyang, Liaoning, 110001, P.R. China. \\ 2. Department of Pediatrics, University of Oklahoma Health Sciences Center, Oklahoma City, OK 73104, USA. \\ $\triangle$ Corresponding authors: Yan Xiaojing, Department of Hematology, The First Affiliated Hospital of China Medical University, No.155, Nanjing North Street, \\ Shenyang, Liaoning, 110001, China. Tel: +86 024 83282501; Fax: +86 024 22703576; E-mail: yanxiaojing_pp@hotmail.com; Shibo Li, 1122 NE 13 Street, Suite 1400,
} Oklahoma City, OK 73104. Tel: +1-405-271-3590; Fax: +1-405-271-7117; Email: Shibo-li@ouhsc.edu.

(C) The author(s). This is an open access article distributed under the terms of the Creative Commons Attribution License (https://creativecommons.org/licenses/by/4.0/). See http:/ /ivyspring.com/terms for full terms and conditions.

Received: 2019.08.14; Accepted: 2019.12.19; Published: 2020.01.18

\begin{abstract}
Background: Hairy cell leukemia $(\mathrm{HCL})$ is a rare chronic B-cell lymphoproliferative disorder. It has two pathological subtypes: classical HCL (HCL-C) and HCL-variant (HCL-V). HCL-C and HCL-V are distinct in morphology and immunophenotype. Their differentiation is important for patient management and clinical outcome, with $\mathrm{HCL}-\mathrm{V}$ responding poorly to conventional $\mathrm{HCL}$ treatments. Recently, whole genomic sequencing has been used to identify the difference between HCL-C and $\mathrm{HCL}-\mathrm{V}$ and mutation of $\mathrm{BRAF}^{\mathrm{V} 600 \mathrm{E}}$ has been proved to be a molecular hallmark of HCL-C. However, BRAF inhibitors were not effective in all HCL-C cases and HCL-V seems be lack of the high-frequency mutations. Therefore, it is necessary to compare the genomic changes between HCL-C and HCL-V by high-resolution studies, especially in Chinese population, the genomic alterations of $\mathrm{HCL}$ have rarely be reported.

Methods: In this study, the clinical features of a total of 18 Chinese $\mathrm{HCL}$ patients were described. Single nucleotide polymorphism (SNP) array analysis was performed to evaluate the genomic copy number alterations (CNA) and copy neutral loss of heterozygosity $(\mathrm{CN}-\mathrm{LOH})$ on six $\mathrm{HCL}-\mathrm{Vs}$ with CD25/BRAF ${ }^{\mathrm{V} 600 \mathrm{E}-}$ and four $\mathrm{HCL}-\mathrm{Cs}$ with $\mathrm{CD}^{2} 5^{+} / \mathrm{BRAF}^{\mathrm{V} 600 \mathrm{E}+}$.

Results: A total of 24 CNAs including seven chromosomal gains and 17 chromosomal losses, and $22 \mathrm{CN}-\mathrm{LOHs}$ were revealed. Five of the six cases of HCL-V showed $15 \mathrm{CNAs}$ including four cryptic chromosomal gains and 11 chromosomal losses. Overlapping regions involving micro-deletion of chromosome $2 \mathrm{q} 13$ and large chromosomal loss of $14 \mathrm{q}$ were showed in HCL-V. In HCL-C, a total of nine CNAs were revealed in three of the four cases including three chromosomal gains and six chromosomal losses. No overlapping area was observed among the CNVs. $15 \mathrm{CN}-\mathrm{LOHs}$ were showed in five of the six cases of HCL-V and seven CN-LOHs was demonstrated in all of the four HCL-Cs.

Conclusions: Comparing to Westerners, a relatively higher proportion of HCL-V in all HCL is observed in this study. CNAs and CN-LOHs were common in both HCL-V and HCL-C but the CNAs were different in them. HCL-C was characterized with the higher ratio of large chromosomal changes but lacked of recurrent CNAs, while HCL-V was presented with the higher incidence of cryptic CNAs and recurrent CNAs involving tumor-associated genes. It is necessary to further investigate the association of the genes, such as NPHPI and TRAF3 genes, and HCL-V in the future study.
\end{abstract}

Key words: genomic copy numbers, hairy cell leukemia-variant, classical hairy cell leukemia 


\section{Introduction}

Hairy cell leukemia (HCL) is an uncommon chronic B-cell lymphoproliferative disorder that is characterized by aggregation of clonal small mature B lymphocytes with "hairy" projections on the cell surface in peripheral blood, bone marrow and spleen. Since HCL-variant(HCL-V) was first reported by Cawley et al. in 1980, the indolent form of classical HCL (HCL-C) and the more aggressive HCL-V (accounting for $10 \%$ of all HCL) has been included in HCL reporting for at least two decades (1-2). HCL-C and HCL-V share some common pathological features with each other but also differ in the hairy cell morphology, immunophenotype, response to conventional HCL treatments and disease courses [3-5]. In 2008, HCL-V was included in the World Health Organization (WHO) classification as a provisional entity and is no longer considered to be biologically related to HCL-C [6]. Therefore, identification of biological differences is essential to illuminate the underlying distinctions between HCL-V and HCL-C.

Current research in the field of HCL is focused on identifying novel and potential genomic aberrations which serve as specific diagnostic markers and therapeutic targets. Whole-exome sequencing made a great advancement in this area. In 2011, the activating $B R A F^{\mathrm{V} 600 \mathrm{E}}$ mutation was found in all 47 patients with HCL [7]. Further studies not only confirmed this finding but also identified that it was absent in both HCL-V and HCL-C accompanied with the IGHV4-34 molecular variant [8-9]. Now, the $B R A F^{\mathrm{V} 600 \mathrm{E}}$ mutation has been a molecular hallmark and a treatment target of HCL-C [10-11]. Recently, a high prevalence of MAP2K1 mutation was observed in HCL-V and VH4-34+-HCL but not in HCL-C [12]. However, other forms of genomic aberrations still need to be clarified because the activating MAP2K1 mutation only occur in 50\% of HCL-V and BRAF inhibitors were not effective in all HCL cases[13].

HCL lacks balanced chromosomal abnormalities. Moreover, traditional banding analysis is frequently inconclusive due to chromosome condensation, imperfect banding and the presence of just a few metaphases. Genome-wide single-nucleotide polymorphism (SNP) arrays containing hundreds of thousands of SNPs from the human genome have proven useful for studying hematologic malignancies [14]. Data quality of SNP arrays plays a key role in the accuracy and precision of unbalanced genomic aberrations and copy neutral loss of heterozygosity (CN-LOH) analyses. SNP array-based karyotyping was used in this study to identify the unbalanced chromosomal alterations in HCL, especially those cryptic alterations which are less than $5 \mathrm{Mb}$ in size and invisible in traditional G-banding.

\section{Methods}

\section{Patients}

Patients with HCL admitted to the First Affiliated Hospital of China Medical University from January of 2013 to December of 2016 were investigated in this study. All patients underwent bone marrow aspiration and biopsy. Referring to the 2008 World Health Organization (WHO) classification and previous studies, the diagnostic criteria of HCL-C or HCL-V was made: (1) lymphoid cells with hairy projections involving peripheral blood or bone marrow, (2) the pattern of interstitial or patchy infiltration in bone marrow biopsies,(3) the expression of $B$ cell surface markers of (CD20) and the four markers (CD11c, CD25, CD103 and CD123) define the HCL score and (4) excluding other B cell hematological disorders[6, 13,15-16].

\section{Morphology examination}

Blood examination for all patients included complete blood counts and peripheral blood smears. Hairy cell morphology was described by bone marrow smear stains and bone marrow biopsies.

\section{Immunophenotype}

Hairy cell phenotypes were determined by flow cytometry analysis of leukemic cells in bone marrow or peripheral blood. The expression panel of cell surface markers included CD19, CD20, CD22, CD23, CD25, CD11c, CD103, CD123, CD5 and FMC7 and $k / \lambda$ light chain classes were also determined.

\section{Single nucleotide polymorphism (SNP) array}

DNA was extracted from bone marrow or peripheral blood mononuclear cells using the QiaAmp DNA Blood Minikit (Qiagen, Hilden, Germany). The DNA copy number and SNP analyses were performed with CytoScan ${ }^{\circledR}$ Array $(n=5)$ from Affymetrix ${ }^{\circledR}$ Protocols supplied by the manufacturer were followed. The Affymetrix $₫ 450$ fluidics station and GeneChip ${ }^{\circledR}$ Scanner $30007 \mathrm{G}$ were used to wash, stain and scan the arrays.

SNP array data were analyzed using annotations of genome version GRCh37 (hg19) and were also compared to the Gene Expression Omnibus (GEO) database (accession number GSE67460). Detailed visual data analysis was performed in all samples, in addition to software-reported alterations. Only copy number aberrations (CNAs) with a gain more than $400 \mathrm{~Kb}$, a loss of more than $200 \mathrm{~Kb}$ and a $\mathrm{LOH}$ more than $100 \mathrm{~Kb}$ and a minimum of 10 aberrant probes were selected. Detected CNAs were compared to the 
Database of Genomic Variants (http://dgv.tcag.ca/ $\mathrm{dgv} / \mathrm{app} /$ home) and an internal control series $(n=1,000)$ provided by Affymetrix®in order to distinguish the somatic origin of CNAs from constitutional copy number variants (CNVs).

\section{BRAF ${ }^{600 E}$ mutation analysis}

The mutation status of BRAF was assayed using Sanger sequencing in YuanQi Biomedical Technology Company (Shanghai, China). DNA was extracted from bone marrow or peripheral blood with DNeasy Blood \& Tissue Kit (Qiagen, Inc.) for Sanger sequencing by Leukemia Related Gene Test Kit (Shanghai Yuanqi Bio-Pharmaceutical Co., Ltd.). PCR reactions were carried out in a final volume of $25 \mu \mathrm{l}$ containing $3 \mu \mathrm{l}$ genomic DNA, $9 \mu \mathrm{l}$ sequencing reaction, and 13 $\mu 1$ PCR MIX3 (Shanghai Yuanqi Bio-Pharmaceutical Co., Ltd.). Samples were processed at $42^{\circ} \mathrm{C}$ for $5 \mathrm{~min}$ and at $94^{\circ} \mathrm{C}$ for $5 \mathrm{~min}$, followed by 40 cycles at $94^{\circ} \mathrm{C}$ for $30 \mathrm{sec}, 58^{\circ} \mathrm{C}$ for 30 $\mathrm{sec}$, and $72^{\circ} \mathrm{C}$ for $60 \mathrm{sec}$, with a final step for $5 \mathrm{~min}$ at $72^{\circ} \mathrm{C}$. PCR products were loaded on agarose gels, purified using BigDye Terminators and sequenced on ABI 3500 Genetic Analyzer.

\section{Results}

\section{Epidemiology and clinical features}

A total of 18 patients including 12 HCL-C and 6 HCL-V were diagnosed in the First Affiliated Hospital of China Medical University from 2013 to 2016. These 18 cases accounted for $1.9 \%$ of all the adult leukemia (acute myeloid /lymphoblastic leukemia and chronic myeloid leukemia, $n=967$ ) cases and $4.8 \%$ of all the lymphoma (non-Hodgkin's and Hodgkin's lymphoma, $n=376$ ) cases diagnosed at this hospital during this time span. The median age at diagnosis was 59.5 years (37-87 years old). The ratio of male to female was 8:1. Fever and fatigue were the most common presentations and splenomegaly was frequently observed on physical examination. The comparisons of clinical features between HCL-C and HCL-V are summarized in Table 1.

\section{Morphology of hairy cells}

Of the 18 patients, 13 of them showed hypercellular bone marrow and three showed hypocellular bone marrow. Failure to collect bone marrow from two patients occurred due to dry tap. The median ratio of hairy cells was $55.5 \%$ ranged from $30.8 \%$ to $91.4 \%$ in peripheral blood or bone marrow. The cells were round in shape and varied in size from small to medium. The cytoplasm was abundant with irregular villiform projections. The nuclei were round, oval or reniform with a clear nuclear membrane and coarse reticular chromatin. Bone marrow biopsies from six patients showed lymphoid cells were spread out diffusely with abundant and clear cytoplasm which made wide spaces between the nuclei. Bone marrow fibrosis was observed in the two patients who had dry tap.

\section{Immunophenotype}

All of the patients showed mature B lymphocyte immunophenotype with strong expression of CD19, CD20, CD22 and CD11c and restrictive expression of $\mathrm{k}$ or $\lambda$ light chains. The cells were also positive for FMC7 $(n=14)$ and CD103 $(n=15)$. All patients with HCL-C had CD25 expression, which was not presented in the six patients with HCL-V. The CD5 marker was negative in all patients except one (case \#1 in HCL-C group) who had positive expression of CD103, FMC7 and CD25. None demonstrated positive expression of CD10. The characteristics of immunophenotype were summarized in Table 2.

Table 1. Clinical features of patients with HCL

\begin{tabular}{lll}
\hline & HCL-C & HCL-V \\
\hline Total number & 12 & 6 \\
Median Age (range) & $61(38-87)$ & $59(37-69)$ \\
Male/Female & $11 / 1$ & $5 / 1$ \\
Fever & 6 & 1 \\
Fatigue & 4 & 1 \\
Splenomegaly & 12 & 6 \\
Lymphadenopathy & 4 & 2 \\
Pancytopenia & 7 & 0 \\
PB count median (range) & & \\
WBC $\left(\times 10^{9} / \mathrm{L}\right)$ & $3.38(1.33 \sim 128.54)$ & $59.6(14.39 \sim 223.16)$ \\
Hb (g/L) & $88(53 \sim 137)$ & $133(91 \sim 167)$ \\
Platelet $\left(\times 10^{9} / \mathrm{L}\right)$ & $62(35 \sim 105)$ & $122(81 \sim 193)$ \\
Hairy cell $(\%)$ & $46.95(30.8 \sim 89.5)$ & $66.05(36.4 \sim 91.4)$ \\
\hline
\end{tabular}

PB: Peripheral Blood; WBC: White blood cell; Hb: hemoglobin

Table 2. The immunophentypes of 6 cases of HCL-V and 12 cases of HCL-C

\begin{tabular}{|c|c|c|c|c|c|c|c|}
\hline Case No. & CD11c & CD25 & CD103 & CD123 & CD23 & FMC7 & $\mathrm{CD} 5$ \\
\hline \multicolumn{8}{|c|}{ HCL-C (n=12) } \\
\hline 1 & ++ & + & + & - & - & ++ & ++ \\
\hline 2 & ++ & + & ++ & / & - & ++ & - \\
\hline 3 & ++ & + & ++ & ++ & - & ++ & - \\
\hline 4 & ++ & + & ++ & ++ & - & ++ & - \\
\hline 5 & ++ & ++ & ++ & - & - & ++ & - \\
\hline 6 & + & + & ++ & / & - & - & - \\
\hline 7 & ++ & + & ++ & ++ & + & + & - \\
\hline 8 & ++ & ++ & ++ & / & - & ++ & - \\
\hline 9 & ++ & ++ & ++ & - & ++ & ++ & - \\
\hline 10 & ++ & ++ & ++ & ++ & - & ++ & - \\
\hline 11 & ++ & + & ++ & / & ++ & - & - \\
\hline 12 & ++ & ++ & + & + & - & - & - \\
\hline \multicolumn{8}{|c|}{ HCL-V $(n=6)$} \\
\hline 1 & ++ & - & - & - & - & ++ & - \\
\hline 2 & ++ & - & + & / & - & + & - \\
\hline 3 & ++ & - & + & - & + & ++ & - \\
\hline 4 & ++ & - & ++ & - & - & - & - \\
\hline 5 & ++ & - & - & - & - & + & - \\
\hline 6 & ++ & - & - & - & - & ++ & - \\
\hline
\end{tabular}


Table 3. Genomic aberrations identified by single nucleotide polymorphism (SNP) array analysis

\begin{tabular}{|c|c|c|c|c|c|}
\hline & Case & Chromosomal aberration & Chromosome & Genomic Annotation (bp) GRCh37 & Size $(\mathbf{M b})$ \\
\hline \multirow[t]{30}{*}{ HCL-V (n=6) } & $\# 1$ & $\mathrm{CN}-\mathrm{LOH}$ & $17 q 22 q 25.3$ & $54,265,339-81,041,823$ & 26.776 \\
\hline & \multirow[t]{4}{*}{ \# 2} & Loss & 2q13 & $110,477,792-111,392,259$ & 0.914 \\
\hline & & Loss & $14 q 32.13 q 32.33$ & $96,207,358-105,637,747$ & 9.430 \\
\hline & & CN-LOH & 3p21.31 & $48,186,267-50,174,572$ & 1.988 \\
\hline & & CN-LOH & 19q13.2 & $42,198,558-43,371,294$ & 1.173 \\
\hline & \multirow[t]{8}{*}{ \# 3} & Loss & $14 q 32.13 q 32.33$ & $96,182,616-106,237,059$ & 10.054 \\
\hline & & Loss & 17q11.2 & $27,902,488-31,078,344$ & 3.176 \\
\hline & & Loss & 20p12.1 & $15,101,464-15,207,464$ & 0.106 \\
\hline & & CN-LOH & $9 \mathrm{q} 31.1$ & $103,873,786-105,991,203$ & 2.117 \\
\hline & & CN-LOH & 10p14p13 & $10,249,027-13,875,590$ & 3.627 \\
\hline & & $\mathrm{CN}-\mathrm{LOH}$ & 11q13.1q13.2 & $65,399,528-66,842,469$ & 1.443 \\
\hline & & $\mathrm{CN}-\mathrm{LOH}$ & $12 \mathrm{q} 24.31$ & $121,944,131-124,325,360$ & 2.381 \\
\hline & & $\mathrm{CN}-\mathrm{LOH}$ & 19q13.2q13.31 & $42,471,566-43,807,152$ & 1.336 \\
\hline & \multirow[t]{2}{*}{$\# 4$} & Loss & $2 \mathrm{q} 11.2 \mathrm{q} 13$ & $102,236,088-113,269,612$ & 11.033 \\
\hline & & Loss & $22 \mathrm{q} 11.22$ & $22,724,607-23,121,204$ & 0.397 \\
\hline & \multirow[t]{9}{*}{ \# 5} & Loss & $5 q 11.2$ & $55,509,576-56,265,992$ & 0.756 \\
\hline & & Loss & $6 \mathrm{p} 21.33$ & $31,360,255-31,453,640$ & 0.093 \\
\hline & & Gain & $6 q 16.1$ & $94,567,726-95,262,849$ & 0.695 \\
\hline & & Gain & $11 \mathrm{q} 23.3$ & $117,954,250-118,038,741$ & 0.084 \\
\hline & & Loss & $14 \mathrm{q} 32.33$ & $106,391,073-107,216,306$ & 0.825 \\
\hline & & Loss & $19 q 13.12$ & $37,285,393-37,469,098$ & 0.184 \\
\hline & & $\mathrm{CN}-\mathrm{LOH}$ & $2 q 32.1 q 32.2$ & $188,962,426-190,835,473$ & 1.873 \\
\hline & & CN-LOH & $16 p 11.2$ & $29,912,902-31,411,185$ & 1.498 \\
\hline & & $\mathrm{CN}-\mathrm{LOH}$ & 19q13.2q13.31 & $42,390,241-43,695,840$ & 1.306 \\
\hline & \multirow[t]{6}{*}{$\# 6$} & Gain & $7 \mathrm{q} 36.2$ & $153,397,733-153,670,448$ & 0.273 \\
\hline & & Gain & $18 \mathrm{q} 21.2 \mathrm{q} 21.31$ & $53,630,341-53,899,387$ & 0.269 \\
\hline & & $\mathrm{CN}-\mathrm{LOH}$ & $6 \mathrm{p} 22.2$ & $26,089,334-27,491,299$ & 1.402 \\
\hline & & $\mathrm{CN}-\mathrm{LOH}$ & 10p11.21q11.21 & $37,737,079-44,015,746$ & 6.279 \\
\hline & & CN-LOH & $11 \mathrm{q} 22.2 \mathrm{q} 22.3$ & $102,495,998-104,924,246$ & 2.428 \\
\hline & & $\mathrm{CN}-\mathrm{LOH}$ & Xq13.1q13.3 & $71,586,774-75,087,152$ & 3.500 \\
\hline \multirow[t]{16}{*}{ HCL-C (n=v) } & \multirow[t]{5}{*}{$\# 1$} & Loss & $3 q 27.1$ & $183,660,585-184,626,909$ & 0.966 \\
\hline & & Loss & 7q11.21q11.22 & 66,377,234-159,114,952 & 92.738 \\
\hline & & Gain & $17 \mathrm{q} 11.2 \mathrm{q} 25.3$ & $26,125,918-81,046,413$ & 54.920 \\
\hline & & $\mathrm{CN}-\mathrm{LOH}$ & 11p11.2q12.1 & $48,102,867-56,086,147$ & 7.983 \\
\hline & & $\mathrm{CN}-\mathrm{LOH}$ & $16 q 21 q 22.1$ & $66,242,376-69,516,168$ & 3.274 \\
\hline & $\# 2$ & $\mathrm{CN}-\mathrm{LOH}$ & $6 \mathrm{p} 22.2 \mathrm{p} 22.1$ & $25,622,212-27,670,917$ & 2.049 \\
\hline & \multirow[t]{5}{*}{ \#3 } & Loss & $7 \mathrm{q} 21.11$ & $80,040,648-80,211,718$ & 0.171 \\
\hline & & Loss & $14 q 32.33$ & $106,467,544-106,803,397$ & 0.336 \\
\hline & & Loss & Xp22.31 & $6,456,940-8,135,053$ & 1.678 \\
\hline & & CN-LOH & $1 \mathrm{q} 43$ & $239,313,573-242,808,496$ & 3.495 \\
\hline & & CN-LOH & 15q15.1q21.1 & $42,437,431-45,090,821$ & 2.653 \\
\hline & \multirow[t]{5}{*}{$\# 4$} & Gain & $5 q 11.1 q 35.2$ & $49,708,187-173,216,595$ & 123.508 \\
\hline & & Loss & Monosomy 21 & & \\
\hline & & Gain & 22q11.23q12.1 & $25,687,568-25,910,879$ & 0.223 \\
\hline & & CN-LOH & $3 p 21.31$ & $47,608,097-49,554,285$ & 1.946 \\
\hline & & $\mathrm{CN}-\mathrm{LOH}$ & $9 \mathrm{q} 31.1$ & $105,323,892-107,571,241$ & 2.247 \\
\hline
\end{tabular}

\section{Genomic aberrations}

The mutation status of BRAF gene was assayed in ten cases. BRAFV600E mutation was demonstrated in four cases of HCL-C (case \#7, 8, 9, 10) and wild type of BRAF was proved in all of the six HCL-Vs. SNP array analysis was performed on the ten cases and a total of 24 chromosomal number variations (CNVs) including seven chromosomal gains and 17 chromosomal losses, and 22 copy neutral loss of heterozygosity $(\mathrm{CN}-\mathrm{LOH})$ were revealed (Table 3 and Figure 1). There were no overlapping $\mathrm{CNV}$ regions between the HCL-V and the HCL-C. In HCL-V, a total of 15 CNAs was identified in five of the six cases. All of the four chromosomal gains were cryptic, involving chromosome $6,11,7$ and 18 . The majority of the 11 chromosomal losses were micro-deletions $(<1 \mathrm{Mb}$ in size, $n=7)$, whereas losses in large size $(>5 \mathrm{Mb}$ in size, $n=3$ ) was not rare. Overlapping regions were showed as micro-deletion of chromosomes 2q13 (2q13: $110,477,792-111,392,259, \quad 0.914 \mathrm{Mb})$ encompassing some interesting genes such as NPHP1, RGPD6 and LIMS4 and large chromosomal loss of $14 \mathrm{q}$ (14q32.13q32.33:96,207,358-105,637,747, 9.430Mb). In HCL-C, a total of nine CNAs were revealed in three of the four cases. Large chromosomal changes were common, including two of the three chromosomal gains and two of the six chromosomal losses. No overlapping area was observed among the CNVs. 15 $\mathrm{CN}-\mathrm{LOH}$ were showed in five of the six cases of HCL-V and seven CN-LOHs was demonstrated in all of the four HCL-Cs. The ratio of CN-LOH to CNV was 
1:1 in HCL-V and 7:9 in HCL-C. The median size of $\mathrm{CN}-\mathrm{LOH}$ was $1.988 \mathrm{Mb}(1.173-26.776 \mathrm{Mb})$ in HCL-V and $2.653 \mathrm{Mb}(1.946-7.983 \mathrm{Mb})$ in HCL-C. CN-LOH of $19 q 13.2(42,471,566-43,371,294,0.900 \mathrm{Mb})$ was the overlapping region observed in HCL-V, containing interesting genes such as POU2F2, DEDD2, GSK3A, ERF, CIC, CXCL17, CEACAM1 and PSG. Overlapping area of $\mathrm{CN}-\mathrm{LOH}$ was absence in HCL-C.

\section{Discussion}

The term HCL is derived from observations that the clonal expansion of mature B cell had hair-like villi on the cell surface and frequently infiltrated the bone marrow, spleen and liver. Currently, HCL is classified by the WHO under B-cell non-Hodgkin's lymphoma [17]. HCL rarely occurs in either leukemia or lymphoma. A ten-year study from the United States of America showed that HCL accounted for $4.4 \%$ of all adult leukemia and $1.1 \%$ of all lymphoma cases [18]. In our study, the incidence of HCL in leukemia was lower than that in America, but it was higher in lymphoma. Incidency of HCL-V was higher, constituting $33.3 \%$ of all HCL cases in this study, while the proportion was $10 \%$ in Western countries [19]. A similar prevalence was also observed in Taiwan, which demonstrated that the HCL-V occurs more frequently in Asian populations, while HCL-C is rare [20].
Clinically, it is difficult to differentiate HCL-C and HCL-V as they share many common presentations such as fever, anemia, splenomegaly and enlargement of lymph nodes. Immunophenotypes can help distinguish HCL-V from HCL-C with the typical markers panel [21-22]. In our study, differentiation between HCL-V and HCL-C was made using the marker panel with CD23, CD123, CD25 and CD103. The specific molecular hallmark is the BRAFV600E mutation which is observed in almost all patients of HCL-C but negative in other B-cell malignancies including HCL-V [23-24]. As a serine/threonine kinase, BRAF is a member of the RAF family and involved in the mitogen-associated protein kinase (MAPK) signaling pathway [25-26]. Therefore, BRAF is not only a disease-defining marker of HCL-C but is also a therapeutic target for BRAF inhibitors. In contrast, the molecular landmark of HCL-V is not known. Recently, activating mutations in the MAP2K1 gene were reported in ten of twenty-four HCL-V cases and in five of seven HCL-C cases that were IGHV4-34+ by means of whole exome sequencing [12]. However, another study confirmed that the MAP2K1 mutation in HCL-V was not as high as $42 \%$ and it was also observed in splenic B-cell lymphoma/leukemia (unclassifiable) (SBCLL-U) [27]. This indicates that sequencing analysis is not enough to delineate the genetic network of HCL.

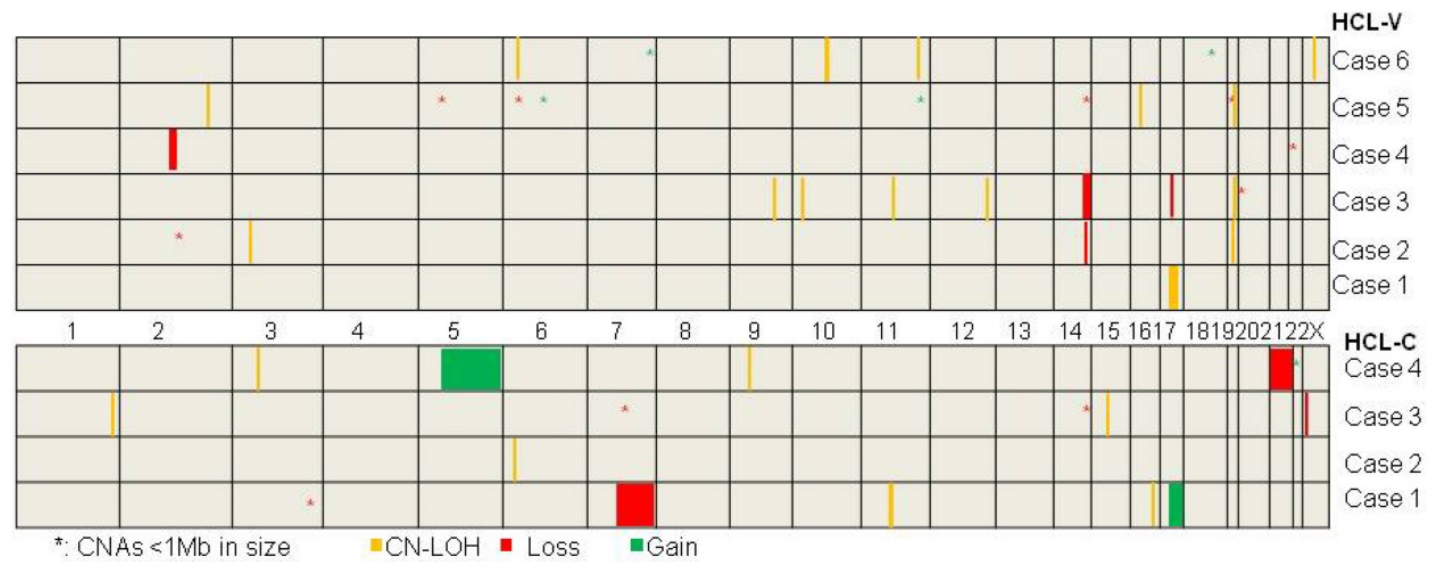

Figure 1. The delineation of genomic CNAs and CN-LOH in six HCL-Vs and four HCL-Cs by SNP-array analysis.

Table 4. Comparison of genomic CNAs between this study and other published studies

\begin{tabular}{|c|c|c|c|c|c|c|c|c|}
\hline \multirow[t]{2}{*}{ Author/Year } & \multicolumn{4}{|l|}{ HCL-C* } & \multicolumn{4}{|l|}{ HCL-V } \\
\hline & Aberration & Loss & Gain & $\mathrm{LOH}$ & Aberration & Loss & Gain & $\mathrm{LOH}$ \\
\hline \multirow[t]{2}{*}{ Hockley et al./2011 } & NO. & 28 & 19 & 21 & NO. & 81 & 37 & 57 \\
\hline & Recurrent ${ }^{* *}$ & $7 q, 21 q$ & $12 \mathrm{p}$ & - & Recurrent & $\begin{array}{l}3 p, 6 q, 7 q, 8 p, 14 q, 17 p \\
19 p\end{array}$ & $5,5 q, 12 q, 17 q$ & - \\
\hline \multirow[t]{2}{*}{ Rinaldi et al./2013 } & NO. & 2 & 0 & 0 & NO. & - & - & - \\
\hline & Recurrent & 0 & 0 & - & Recurrent & - & - & - \\
\hline \multirow{2}{*}{$\begin{array}{l}\text { Zhang et al./The present } \\
\text { study }\end{array}$} & NO. & 6 & 3 & 7 & NO. & 11 & 4 & 15 \\
\hline & Recurrent & 0 & 0 & - & Recurrent & $2 q, 14 q$ & 0 & - \\
\hline
\end{tabular}

*cases with HCL-C or HCL with BRAFv600E+

${ }^{* *}$ Chromosomes with overlapping regions of deletion/gain occurring in $\geq 2$ cases 
Chromosomal copy number aberrations (CNAs) are common in lymphoid malignancies, but conventional cytogenetic analysis is frequently limited by tumor cell culture. In recent years, gene chip technology has been used to determine genomic unbalanced changes in leukemia cells [28-29]. However, its application in HCL is limited, especially in Asian countries which have unique clinicopathologic features of HCLs [20]. The diagnosis of HCL-V and HCL-C in this study was confirmed by typical morphology, immunophenotype as well as BRAFV600E mutation status. SNP array analysis was applied on HCL-Vs with CD25-/BRAFV600E- and HCL-Cs with $\mathrm{CD}^{2} 5^{+} / \mathrm{BRAFV}^{\mathrm{C} 00 \mathrm{E}}+$. The high incidence of CNA as well as CN-LOH in both HCL-V and HCL-C cases in this cohort of Chinese patients was consistent with the study of UK reported by Hockley et al. (2011) which identified the CNAs in 11 cases (86\%) of HCL-C and 14 cases (93\%) of HCL-V [30]. However, Rinaldi and his colleagues (2013) showed that the incidence of CNAs in HCL-C was extremely low; only two genomic losses were detected in 19 cases of HCL-C [31]. They concluded that the presence of genetic damages was low in HCL-C due to the high recurrence of the $\mathrm{V} 600 \mathrm{E}$ inducing deregulated activity of the BRAF gene. Moreover, this study presented distinct genomic aberrations, in contrast with the study from UK which showed gain of $5 q$, deletion of $7 q$ and deletion of $17 p$ (including TP53) were recurrent aberrations in HCL[30]. It was assumed that gain of $5 q$ and deletion of $7 q$ were resulted from the TP53-related genomic instability since they coexisted with $17 \mathrm{p}$-. However, in this study, $5 q^{+}$and $7 q-$ were not recurrent CNAs and found respectively in two cases which showed no concurrent 17p- involving TP53 (Table 4).

In addition, distinct $\mathrm{CNAs}$ and $\mathrm{CN}-\mathrm{LOH}$ changes were presented in HCL-V and HCL-C. It was characterized with the chromosomal loss and cryptic chromosomal alterations which were undetectable with traditional cytogenetic approaches. Especially, the ratio of large chromosomal change was higher in HCL-C, while HCL-V was more frequently contained cryptic CNAs. Moreover, HCL-V carried recurrent chromosomal abnormalities such as micro-deletion of chromosomes 2q13 and large chromosomal loss of 14q. NPHP1, locating at 2q13, complete deletion of this gene might cause nephronophthisis [32]. The contribution to tumorigenesis of this gene is not known. However, since this gene encodes a protein with a SRC homology 3 (SH3) domain, which plays a role in cell division as well as in cell-cell and cell-matrix adhesion signaling, the association between NPHP1 and HCL-V was worth investigating. The recurrent large chromosomal deletion of
$14 q 32.13 q 32.33$ in this study partially overlaps with an area in $\operatorname{del}(14)(\mathrm{q} 24.1 \mathrm{q} 32.33)$ which is the recurrent chromosomal aberration in CLL and B cell lymphoma [33]. One of the cases of HCL-V in Hockley's study also has been revealed to contain a microdeletion of 14q32.32[30]. A key tumor suppressor gene, TRAF3, is located within the deleted region. The protein encoded by this gene is a member of the TNF receptor associated factor (TRAF) protein family which is a critical component of the lymphotoxin- $\beta$ receptor (LT $\beta \mathrm{R})$ signaling complex. This complex induces nuclear factor kappa B (NF-kB) and cell death is initiated by LT $\beta$ ligation[34-35].

In conclusion, this study showed a higher incidence of HCL-V in the cohort of Chinese patients with HCL. The delineation of the genomic CNAs and $\mathrm{CN}-\mathrm{LOHs}$ demonstrated the difference between HCL-V and HCL-C at the molecular level. The HCL-C showed higher ratio of large chromosomal changes but lacked of recurrent CNAs, on one hand supporting the driver mutation role of $\mathrm{BRAF}^{\mathrm{V} 600 \mathrm{E}}$ mutation, on the other hand suggesting that the effectiveness of BRAF inhibitors might not be observed in all HCL-C. The higher incidence of CNAs in HCL-V cases in this study suggests a higher heterogeneity in HCL-V. The recurrent micro-deletion of chromosomes 2q13 and large chromosomal loss of $14 q 32$ shed light on the potential target of HCL-V such as NPHP1 and TRAF3 genes. It is necessary to clarify the association of these genes and HCL in the future study. Differentiation between HCL-C and HCL-V at the molecular target level could be important for identifying potential agents to improve results with HCL-V.

\section{Acknowledgements}

This work was supported by the National Natural Science Foundation of China (grant number (81600117).

\section{Competing Interests}

The authors have declared that no competing interest exists.

\section{References}

1. Cawley JC, Burns GF, Hayhoe FG. A chronic lymphoproliferative disorder with distinctive features: a distinct variant of hairy-cell leukaemia. Leuk Res. 1980;4(6):547-59.

2. Matutes E, Wotherspoon A, Catovsky D. The variant form of hairy-cell leukaemia. Best Pract Res Clin Haematol. 2003;16(1):41-56.

3. Robak T. Hairy-cell leukemia variant: recent view on diagnosis, biology and treatment. Cancer Treat Rev. 2011;37(1):3-10.

4. Matutes E, Martínez-Trillos A, Campo E. Hairy cell leukaemia-variant: Disease features and treatment. Best Pract Res Clin Haematol. 2015;28(4):253-63.

5. Jain P, Pemmaraju N, Ravandi F. Update on the biology and treatment options for hairy cell leukemia. Curr Treat Options Oncol. 2014;15(2):187-209.

6. Swerdlow S, Campo E, Harris NL, et al. WHO Classification of Tumours of Haematopoietic and Lymphoid Tissues (4th ed.). Lyon: International Agency for Research on Cancer (IARC); 2008:188-90. 
7. Tiacci E, Trifonov V, Schiavoni G, Holmes A, Kern W, Martelli MP, et al. BRAF mutations in hairy-cell leukemia. N Engl J Med. 2011;364(24):2305-15.

8. Tiacci E, Schiavoni G, Forconi F, Santi A, Trentin L, Ambrosetti A, et al. Simple genetic diagnosis of hairy cell leukemia by sensitive detection of the BRAF-V600E mutation. Blood. 2012;119(1):192-5.

9. Xi L, Arons E, Navarro W, Calvo KR, Stetler-Stevenson M, Raffeld M, et al. Both variant and IGHV4-34-expressing hairy cell leukemia lack the BRAF V600E mutation. Blood. 2012;119(14):3330-2.

10. Grever MR, Blachly JS, Andritsos LA. Hairy cell leukemia: Update on molecular profiling and therapeutic advances. Blood Rev. 2014;28(5):197-203.

11. Dietrich S, Glimm H, Andrulis M, von Kalle C, Ho AD, Zenz T. BRAF inhibition in refractory hairy-cell leukemia. $N$ Engl J Med. 2012;366(21):2038-40.

12. Waterfall JJ, Arons E, Walker RL, Pineda M, Roth L, Killian JK, et al. High prevalence of MAP2K1 mutations in variant and IGHV4-34-expressing hairy-cell leukemias. Nat Genet. 2014;46(1):8-10.

13. Troussard X, Cornet E. Hairy cell leukemia 2018: Update on diagnosis, risk-stratification, and treatment. Am J Hematol. 2017;92(12):1382-90.

14. Palomo L, Xicoy B, Garcia O, Mallo M, Ademà V, Cabezón M, et al. Impact of SNP array karyotyping on the diagnosis and the outcome of chronic myelomonocytic leukemia with low risk cytogenetic features or no metaphases. Am J Hematol. 2016;91(2):185-92.

15. Cornet E, Delmer A, Feugier P, Garnache-Ottou F, Ghez D, Leblond V, et al. French Society of Haematology. Recommendations of the SFH (French Society of Haematology) for the diagnosis, treatment and follow-up of hairy cell leukaemia. Ann Hematol. 2014;93(12):1977-83.

16. Jaffe ES. The 2008 WHO classification of lymphomas: implications for clinical practice and translational research. Hematology Am Soc Hematol Educ Program. 2009:523-31.

17. Swerdlow SH, Campo E, Pileri SA, Harris NL, Stein H, Siebert R, et al. The 2016 revision of the World Health Organization classification of lymphoid neoplasms. Blood. 2016;127(20):2375-90.

18. Morton LM, Wang SS, Devesa SS, Hartge P, Weisenburger DD, Linet MS. Lymphoma incidence patterns by WHO subtype in the United States, 1992-2001. Blood. 2006;107(1):265-76.

19. Matutes E, Wotherspoon A, Catovsky D. The variant form of hairy-cell leukaemia. Best Pract Res Clin Haematol. 2003;16(1):41-56.

20. Kao HW, Dunn P, Kuo MC, Shih LY, Lin TL, Wu JH, et al. Classical hairy cell leukemia and its variant: a 17-year retrospective survey in Taiwan Chinese. Acta Haematol. 2011;126(3):186-93.

21. Grever MR, Blachly JS, Andritsos LA. Hairy cell leukemia: Update on molecular profiling and therapeutic advances. Blood Rev. 2014;28(5):197-203.

22. Cornet E, Damaj G, Troussard X. New insights in the management of patients with hairy cell leukemia. Curr Opin Oncol. 2015;27(5):371-6

23. Ahmadzadeh A, Shahrabi S, Jaseb K, Norozi F, Shahjahani M, Vosoughi T, et al. BRAF Mutation in Hairy Cell Leukemia. Oncol Rev. 2014;8(2):253

24. Kreitman RJ. Hairy cell leukemia-new genes, new targets. Curr Hematol Malig Rep. 2013;8(3):184-195.

25. López-Rubio M, Garcia-Marco JA. Current and emerging treatment options for hairy cell leukemia. Onco Targets Ther. 2015;8:2147-56.

26. Tiacci E, Schiavoni G, Martelli MP, Boveri E, Pacini R, Tabarrini A, et al, Constant activation of the RAF-MEK-ERK pathway as a diagnostic and therapeutic target in hairy cell leukemia. Haematologica. 2013;98(4):635-9.

27. Mason EF, Brown RD, Szeto DP, Gibson CJ, Jia Y, Garcia EP, et al. Detection of activating MAP2K1 mutations in atypical hairy cell leukemia and hairy cell leukemia variant. Leuk Lymphoma. 2017;58(1):233-6.

28. Zhang R, Kim YM, Wang X, Li Y, Lu X, Sternenberger AR, et al. Genomic Copy Number Variations in the Myelodysplastic Syndrome and Acute Myeloid Leukemia Patients with $\operatorname{del}(5 q)$ and/or $-7 / \operatorname{del}(7 q)$. Int J Med Sci. 2015;12(9):719-26.

29. Zhang R, Lee JY, Wang X, Xu W, Hu X, Lu X, et al. Identification of Novel Genomic Aberrations in AML-M5 in a Level of Array CGH. PLoS One. 2014;9(4):e87637.

30. Hockley SL, Morgan GJ, Leone PE, Walker BA, Morilla A, Else M, et al. High-resolution genomic profiling in hairy cell leukemia-variant compared with typical hairy cell leukemia. Leukemia. 2011;25(7):1189-92.

31. Rinaldi A, Kwee I, Young KH, Zucca E, Gaidano G, Forconi F, et al. Genome-wide high resolution DNA profiling of hairy cell leukaemia. Br J Haematol. 2013;162(4):566-9.

32. Haghighi A, Savaj S, Haghighi-Kakhki H, Benoit V, Grisart B, Dahan K. Identification of an NPHP1 deletion causing adult form of nephronophthisis. Ir J Med Sci. 2016;185(3):589-95.

33. Nagel I, Bug S, Tönnies H, Ammerpohl O, Richter J, Vater I, et al. Biallelic inactivation of TRAF3 in a subset of B-cell lymphomas with interstitial del(14)(q24.1q32.33). Leukemia. 2009;23(11):2153-5.

34. Bishop GA. TRAF3 as a powerful and multitalented regulator of lymphocyte functions. J Leukoc Biol. 2016;100(5):919-26.

35. Moore CR, Edwards SK, Xie P. Targeting TRAF3 Downstream Signaling Pathways in B cell Neoplasms. J Cancer Sci Ther. 2015;7(2):67-74. 